\title{
Exercise intolerance in comorbid COPD and heart failure: the role of impaired aerobic function
}

\author{
Alcides Rocha ${ }^{1}$, Flavio F. Arbex ${ }^{1}$, Priscila A. Sperandio ${ }^{1}$, Frederico Mancuso ${ }^{2}$, \\ Mathieu Marillier ${ }^{3}$, Anne-Catherine Bernard ${ }^{3}$, Maria Clara N. Alencar ${ }^{1}$, \\ Denis E. O'Donnell ${ }^{3}$ and J. Alberto Neder ${ }^{3}$
}

Affiliations: ${ }^{1}$ Pulmonary Function and Clinical Exercise Physiology Unit (SEFICE), Division of Respirology, Federal University of Sao Paulo, Sao Paulo, Brazil. ${ }^{2}$ Division of Cardiology, Federal University of Sao Paulo, Sao Paulo, Brazil. ${ }^{3}$ Laboratory of Clinical Exercise Physiology and Respiratory Investigation Unit, Queen's University and Kingston General Hospital, Kingston, ON, Canada.

Correspondence: J. Alberto Neder, 102 Stuart Street, Kingston, Ontario, Canada K7L 2V6.

E-mail: alberto.nederđqueensu.ca

@ERSpublications

Impaired aerobic function due to negative cardiopulmonary-muscular interactions is an important determinant of exercise intolerance in patients with comorbid COPD and heart failure http://ow.ly/gveW30nxsUG

Cite this article as: Rocha A, Arbex FF, Sperandio PA, et al. Exercise intolerance in comorbid COPD and heart failure: the role of impaired aerobic function. Eur Respir J 2019; 53: 1802386 [https://doi.org/10.1183/ 13993003.02386-2018].

ABSTRACT Impaired aerobic function is a potential mechanism of exercise intolerance in patients with combined cardiorespiratory disease. We investigated the pathophysiological and sensory consequences of a low change in oxygen uptake $\left(\Delta V^{\prime} \mathrm{O}_{2}\right) /$ change in work rate $(\Delta \mathrm{WR})$ relationship during incremental exercise in patients with coexisting chronic obstructive pulmonary disease (COPD) and systolic heart failure (HF).

After clinical stabilisation, 51 COPD-HF patients performed an incremental cardiopulmonary exercise test to symptom limitation. Cardiac output was non-invasively measured (impedance cardiography) in a subset of patients $(n=18)$.

27 patients presented with $\Delta V^{\prime} \mathrm{O}_{2} / \Delta \mathrm{WR}$ below the lower limit of normal. Despite similar forced expiratory volume in $1 \mathrm{~s}$ and ejection fraction, the low $\Delta V^{\prime} \mathrm{O}_{2} / \Delta \mathrm{WR}$ group showed higher end-diastolic volume, lower inspiratory capacity and lower transfer factor compared to their counterparts $(\mathrm{p}<0.05)$. Peak WR and peak $V^{\prime} \mathrm{O}_{2}$ were $\sim 15 \%$ and $\sim 30 \%$ lower, respectively, in the former group: those findings were associated with greater symptom burden in daily life and at a given exercise intensity (leg discomfort and dyspnoea). The low $\Delta V^{\prime} \mathrm{O}_{2} / \Delta \mathrm{WR}$ group presented with other evidences of impaired aerobic function (sluggish $V^{\prime} \mathrm{O}_{2}$ kinetics, earlier anaerobic threshold) and cardiocirculatory performance (lower oxygen pulse, lower stroke volume and cardiac output $)(p<0.05)$. Despite similar exertional hypoxaemia, they showed worse ventilatory inefficiency and higher operating lung volumes, which led to greater mechanical inspiratory constraints $(\mathrm{p}<0.05)$.

Impaired aerobic function due to negative cardiopulmonary-muscular interactions is an important determinant of exercise intolerance in patients with COPD-HF. Treatment strategies to improve oxygen delivery to and/or utilisation by the peripheral muscles might prove particularly beneficial to these patients.

This article has supplementary material available from erj.ersjournals.com

Received: Dec 162018 | Accepted after revision: Jan 222019

Copyright OERS 2019 


\section{Introduction}

Heart failure with reduced left ventricular ejection fraction (HF) is a common and disabling comorbidity of chronic obstructive pulmonary disease (COPD) [1,2]. There is growing recognition that, despite similar respiratory and cardiac impairment at rest, patients with coexisting COPD-HF have poorer exercise tolerance than their counterparts with COPD or HF [3-5]. Advancing the knowledge on the mechanisms leading to patient's disability is crucial to lessen symptom burden and improve their ability to cope with the demands of daily life [6].

In this context, previous work from our group showed that impairments in leg muscle oxygenation and blood flow on exertion were closely related to a low cardiac output and a heightened sense of leg discomfort in a subset of patients with COPD-HF [3]. In addition, we found that an increased ventilatory response to exercise in COPD-HF (i.e. ventilatory inefficiency $[5,7]$ and exertional oscillatory ventilation [8]) was instrumental to increase the operating lung volumes leading to earlier mechanical-inspiratory constraints and worse dyspnoea at a given work rate (WR) [5, 8]. It is noteworthy that "breathing in excess" at higher lung volumes has important negative haemodynamic consequences (reviewed in [6] and [9]), particularly in patients with already-compromised cardiac function [10]. Impaired oxygen $\left(\mathrm{O}_{2}\right)$ delivery to and/or utilisation by the working skeletal muscles (i.e. aerobic dysfunction) [11,12] constitutes the corollary of those deleterious interactions [13]. It is therefore conceivable that COPD-HF patients with worse haemodynamics at rest who ventilate excessively at higher operating lung volumes on exertion [14] are particularly prone to aerobic dysfunction and to report higher leg discomfort and dyspnoea than patients with preserved aerobic function.

In the present study, we contrasted the sensory and cardiopulmonary responses to exertion in COPD-HF patients presenting or not with impaired aerobic function as indicated by a low versus preserved change in oxygen uptake $\left(\Delta V^{\prime} \mathrm{O}_{2}\right) / \Delta \mathrm{WR}[15,16]$ relationship during incremental exercise. We hypothesised that, compared to those with preserved aerobic function, patients showing a low $\Delta V^{\prime} \mathrm{O}_{2} / \Delta \mathrm{WR}$ ratio would present with worse cardiac function at rest, greater exertional ventilation, higher operating lung volumes and, consequently, a higher burden of symptoms on exertion and on daily life. Confirmation of these hypotheses would shed new light on the key traits of COPD and HF which need to be addressed therapeutically to lessen the growing disability associated with this devastating coexistence [6].

\section{Materials and methods}

\section{Subjects}

We included incremental cardiopulmonary exercise testing data (CPET) from all patients $(\mathrm{n}=51)$ who were prospectively enrolled in studies addressing the pathophysiology of coexisting COPD-HF from March 2015 to December 2018. The specific outcome of the present report (aerobic dysfunction during ramp-incremental CPET) has never been explored in our previous investigations which involved a fraction of these patients (i.e. those assessed up to September 2017); thus, there is no overlap between the current report and the data previously shown in a subset of these patients [3-5]. All patients had an established clinical and functional diagnosis of COPD (post-bronchodilator forced expiratory volume in $1 \mathrm{~s} /$ forced vital capacity ratio below the lower limit of normal and Global Initiative for Chronic Obstructive Lung Disease spirometric stages 2-3) [17] and documented heart failure with reduced left ventricular ejection fraction ( $\leqslant 40 \%$ at the time of diagnosis). They underwent a variable period of clinical stabilisation (ranging from 2 to 8 months) in which their treatment was carefully optimised by cardiologists and respirologists working in academic centres in Brazil and Canada. The original prospective studies which provided the data from the current reported had received ethical approval from the research ethics boards of the Federal University of Sao Paulo Hospital (Sao Paulo, Brazil; \#1151/2015) and Queen's University Affiliated Teaching Hospitals (Kingston, ON, Canada; DMED-1588-13).

\section{Procedures}

Functional capacity and dyspnoea in daily life were assessed by the New York Heart Association (NYHA) classification and the modified Medical Research Council (mMRC) scale, respectively. After transthoracic echocardiography and pulmonary function tests (spirometry, static lung volumes, transfer factor, arterial blood gases) (1085 ELITE D; Medical Graphics, St Paul, MN, USA in Brazil and Vmax229d; SensorMedics, Yorba Linda, CA, USA in Canada), ramp-incremental CPET (SensorMedics Vmax229d system in both laboratories) was conducted on a different day. The rate of WR increase (Ergoline 800s; SensorMedics) was individually selected $\left(5-15 \mathrm{~W} \cdot \mathrm{min}^{-1}\right)$ based on patient's reported level of disability. Key measurements included standard breath-by-breath cardiorespiratory and breathing pattern parameters [18], dynamic operating lung volumes calculated from inspiratory capacity manoeuvres [14], assessment of dyspnoea and leg discomfort intensity (10-point category-ratio Borg scale) and, on a subset of patients, cardiac output by signal morphology impedance cardiography [19]. As detailed in the supplementary material, parameters of aerobic function $\left(V^{\prime} \mathrm{O}_{2}\right.$ kinetics delay at early exercise [15], $\Delta V^{\prime} \mathrm{O}_{2} / \Delta \mathrm{WR}[15]$ and 
peak $V^{\prime} \mathrm{O}_{2}$ (figure 1) and $V^{\prime} \mathrm{O}_{2}$ at the estimated lactate threshold [20]) and ventilatory efficiency $(\Delta$ minute ventilation $\left(V^{\prime} \mathrm{E}\right)-\Delta$ carbon dioxide output $\left(V^{\prime} \mathrm{CO}_{2}\right)$ slope and intercept by linear regression and $V^{\prime} \mathrm{E} / V^{\prime} \mathrm{CO}_{2}$ nadir) [21] were obtained following standard recommendations [22]. A low $\Delta V^{\prime} \mathrm{O}_{2} / \Delta \mathrm{WR}$ was defined according to the sex-specific lower limits of normal [23].

\section{Statistical analysis}

The statistical software package used was IBM SPSS Statistics version 24 (IBM, Armonk, NY, USA). Unpaired t-test (or Mann-Whitney test when appropriate) were used to compare between-subject differences. The Chi-squared test was used to compare frequencies. Association between selected continuous variables was investigated by Pearson's product-moment correlation test. Two-way ANOVA with repeated measures were used to compare symptoms intensity and cardiorespiratory, metabolic, gas exchange and operating lung volumes at rest and iso-WR. A $p<0.05$ level of significance was used for all analyses.

\section{Results}

Clinical and resting characteristics

As expected from the increased prevalence of coronary artery disease in COPD [6], most patients were middle-aged or elderly males with HF secondary to ischaemic heart disease (43 (84.3\%) out of 51). Most frequent comorbidities included non-insulin dependent diabetes mellitus and chronic kidney failure. Patients were under currently recommended therapy for COPD [17] and HF [24] (table 1). From a functional perspective, patients typically presented with moderate to severe airflow limitation, gas trapping and a low transfer factor (table 2).
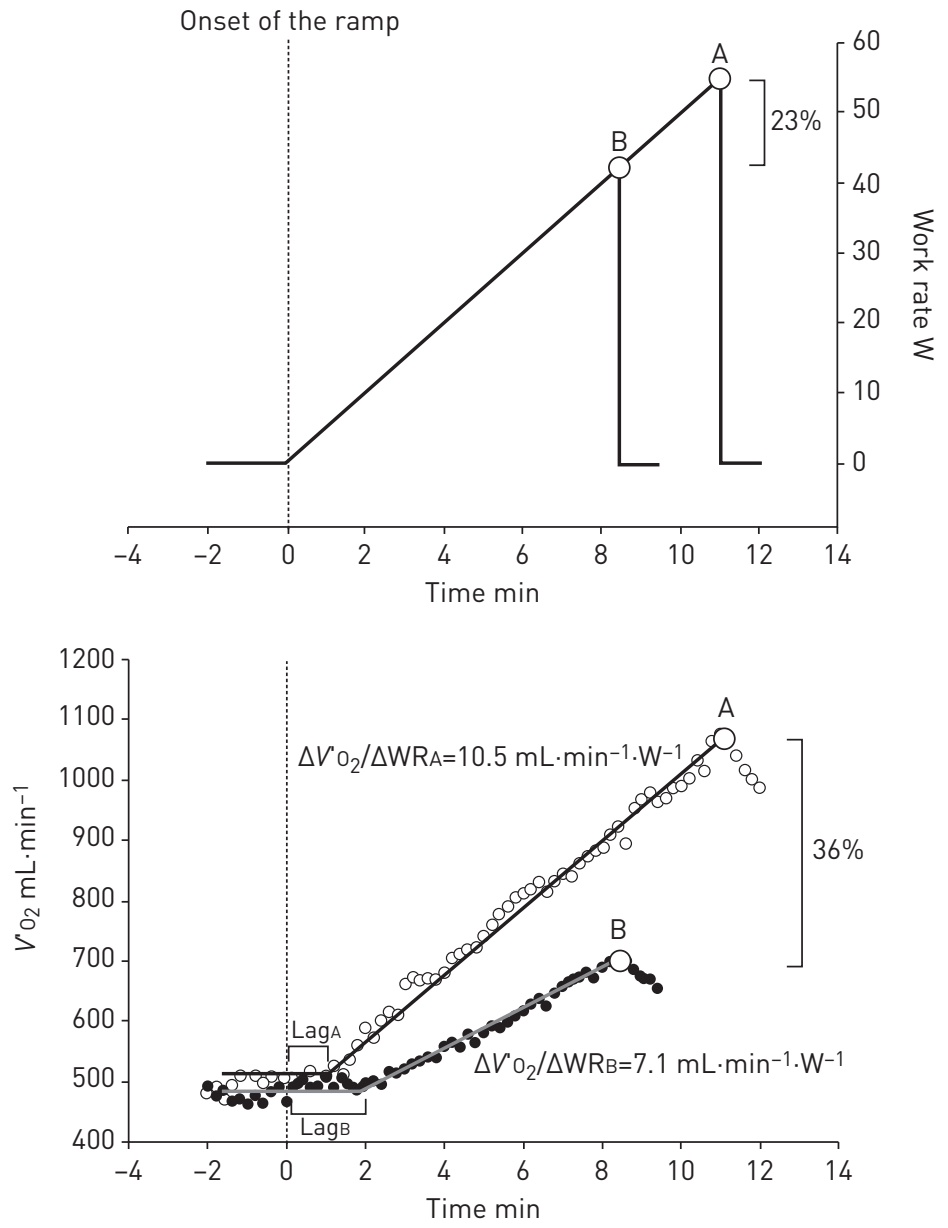

FIGURE 1 Oxygen uptake $\left(\mathrm{V}^{\prime} \mathrm{O}_{2}\right)$ profile (10-s mean) as a function of work rate (WR) in two representative patients with coexistent chronic obstructive pulmonary disease-heart failure: patients $A$ and $B$, presenting with preserved and impaired aerobic function, respectively. Note that as a result of a slower initial "lag phase" (122 s versus $66 \mathrm{~s})$ and a shallow $\Delta V^{\prime} \mathrm{O}_{2} / \Delta$ WR relationship, peak $V^{\prime} \mathrm{O}_{2}$ is appreciably more impaired than peak WR in patient $B$ than in patient $A$. 
TABLE 1 General characteristics of the whole sample of patients with coexistent chronic obstructive pulmonary disease (COPD)-heart failure (HF) and patients separated by the presence or not of aerobic dysfunction based on a low or preserved change in oxygen uptake $\left(\Delta V^{\prime} \mathrm{O}_{2}\right) /$ change in work rate $(\Delta \mathrm{WR})$, respectively

\begin{tabular}{|c|c|c|c|}
\hline & All & Preserved $\Delta V^{\prime} 0_{2} / \Delta W R$ & LoW $\Delta V^{\prime} \mathrm{O}_{2} / \Delta \mathrm{WR}$ \\
\hline Subjects & 51 & 24 & 27 \\
\hline Age years & $67.1 \pm 6.0$ & $66.7 \pm 6.2$ & $67.3 \pm 5.8$ \\
\hline Height $\mathrm{cm}$ & $169 \pm 7$ & $168 \pm 7$ & $169 \pm 8$ \\
\hline Body mass kg & $72.6 \pm 12.1$ & $73.9 \pm 13.8$ & $71.4 \pm 10.9$ \\
\hline Body mass index $\mathrm{kg} \cdot \mathrm{m}^{-2}$ & $25.9 \pm 4.0$ & $26.1 \pm 3.9$ & $25.7 \pm 4.2$ \\
\hline \multicolumn{4}{|l|}{ Clinical } \\
\hline Smoking pack-years & $65 \pm 26$ & $66 \pm 23$ & $64 \pm 30$ \\
\hline NYHA class I/II:III/IV & $26: 25$ & $15: 9$ & $11: 16^{*}$ \\
\hline Ischaemic heart failure & 43 & 20 & 23 \\
\hline mMRC dyspnoea & $3.0(1-5)$ & $2.0(1-4)$ & $3.5(2-5)^{*}$ \\
\hline \multicolumn{4}{|l|}{ Comorbidities } \\
\hline Diabetes & 22 & 10 & 12 \\
\hline $\mathrm{CKD}\left(\mathrm{CrCl}<60 \mathrm{~mL} \cdot \mathrm{min}^{-1}\right)$ & 30 & 13 & 17 \\
\hline \multicolumn{4}{|l|}{ Heart failure treatment } \\
\hline Digoxin & 7 & 3 & 4 \\
\hline Furosemide & 46 & 21 & 25 \\
\hline ACE-I or ARBs & 42 & 19 & 23 \\
\hline Aldosterone blockers & 32 & 15 & 17 \\
\hline Nitrates/hydralazine & 15 & 7 & 8 \\
\hline$\beta$-Blockers & 47 & 22 & 25 \\
\hline Amiodarone & 15 & 8 & 7 \\
\hline \multicolumn{4}{|l|}{ COPD treatment } \\
\hline LAMA & 27 & 13 & 14 \\
\hline LABA & 48 & 22 & 26 \\
\hline ICS (+LABA) & 41 & 20 & 21 \\
\hline \multicolumn{4}{|c|}{$\begin{array}{l}\text { Data are presented as } n, \text { mean } \pm \text { SD or median (range). NYHA: New York Heart Association functional class; } \\
\text { mMRC: modified Medical Research Council scale; CKD: chronic kidney disease; CrCl: creatinine clearance; } \\
\text { ACE-I: angiotensin-converting enzyme inhibitor; ARB: angiotensin receptor blockers; LAMA: long-acting } \\
\text { anti-muscarinic; LABA: long-acting } \beta_{2} \text {-adrenoceptor agonist; ICS: inhaled corticosteroids. *: } p<0.05 \text {. }\end{array}$} \\
\hline
\end{tabular}

A low $\Delta V^{\prime} \mathrm{O}_{2} / \Delta \mathrm{WR}$ relationship was found in 27 (52.9\%) out of 51 patients (see figure 1 for representative subjects and figure 2a for mean data). No significant differences were found for most clinical and functional variables when the groups with preserved versus low $\Delta V^{\prime} \mathrm{O}_{2} / \Delta \mathrm{WR}$ were contrasted $(\mathrm{p}>0.05)$. However, the latter group reported worse functional capacity and dyspnoea in daily life (table 1); moreover, they had lower inspiratory capacity and transfer factor (table 2). Among the echocardiographic variables, only a higher left ventricular end-diastolic diameter separated the low $\Delta V^{\prime} \mathrm{O}_{2} / \Delta \mathrm{WR}$ group from their counterparts (table 2) $(\mathrm{p}<0.05)$.

\section{Metabolic and cardiovascular responses to exertion}

Peak exercise capacity, either expressed as WR or $V^{\prime} \mathrm{O}_{2}$, was significantly reduced in the low $\Delta V^{\prime} \mathrm{O}_{2} / \Delta \mathrm{WR}$ group ( $\mathrm{p}<0.001$ ). However, owing to definition criterion, whereas the former was on average $\sim 15 \%$ $(\sim 10 \mathrm{~W})$ lower in this group, the latter was $\sim 30 \%\left(\sim 0.35 \mathrm{~L} \cdot \mathrm{min}^{-1}\right)$ inferior compared to the preserved $\Delta V$ ${ }^{\prime} \mathrm{O}_{2} / \Delta W R$ group (figure $2 \mathrm{a}$, table 3). A plateau on the $V^{\prime} \mathrm{O}_{2}$ response was found in six patients, all in the low $\Delta V^{\prime} \mathrm{O}_{2} / \Delta \mathrm{WR}$ group. Thus, whereas no patient with preserved $\Delta V^{\prime} \mathrm{O}_{2} / \Delta \mathrm{WR}$ had a severely reduced peak $V^{\prime} \mathrm{O}_{2}(<50 \%$ pred $)$, this finding was observed in $12(44.4 \%)$ out of 27 patients in the low $\Delta V^{\prime} \mathrm{O}_{2} / \Delta \mathrm{WR}$ group. Conversely, $12(46.1 \%)$ out of 26 and three (11.1\%) out of 27 patients with preserved or low $\Delta V^{\prime} \mathrm{O}_{2} /$ $\Delta$ WR had peak $>70 \%$ pred, respectively $(\mathrm{p}<0.05)$.

The low $\Delta V^{\prime} \mathrm{O}_{2} / \Delta \mathrm{WR}$ group presented other evidence of impaired aerobic function, i.e. slower $V^{\prime} \mathrm{O}_{2}$ kinetics and, in those with an identifiable lactate threshold $(\mathrm{n}=27)$, a lower $V^{\prime} \mathrm{O}_{2}$ lactate threshold (table 3); moreover, the respiratory exchange ratio was higher at a given WR (figure 2c) due to a lower $V^{\prime} \mathrm{O}_{2}$ but similar $V^{\prime} \mathrm{CO}_{2}$ (figure $\left.2 \mathrm{~b}\right)(\mathrm{p}<0.05)$. Of note, lower oxygen pulse in this group (figure $2 \mathrm{e}$ ) was associated with higher submaximal heart rate (figure $2 \mathrm{~d}$ ); moreover, stroke volume and cardiac output were reduced in this group compared to their counterparts with preserved $\Delta V^{\prime} \mathrm{O}_{2} / \Delta \mathrm{WR}$ (figure 3). Those metabolic and 
TABLE 2 Resting functional characteristics of chronic obstructive pulmonary disease (COPD)heart failure (HF) patients separated by the presence or not of aerobic dysfunction based on a low or preserved change in oxygen uptake $\left(\Delta V^{\prime} O_{2}\right) /$ change in work rate $(\Delta W R)$, respectively

Preserved $\Delta V^{\prime} 0_{2} / \Delta W R$

Low $\Delta V^{\prime} 0_{2} / \Delta W R$

\begin{tabular}{|c|c|c|}
\hline Subjects & 24 & 27 \\
\hline \multicolumn{3}{|l|}{ Lung function } \\
\hline FEV1 L (\% pred) & $1.64 \pm 0.48(57 \pm 15)$ & $1.58 \pm 0.54(58 \pm 13)$ \\
\hline FVC L (\% pred) & $3.05 \pm 0.59(80 \pm 12)$ & $2.96 \pm 0.68(76 \pm 13)$ \\
\hline $\mathrm{FEV}_{1} / \mathrm{FVC}$ & $0.52 \pm 0.12$ & $0.54 \pm 0.14$ \\
\hline IC \% pred & $83 \pm 14$ & $69 \pm 16^{*}$ \\
\hline TLC \% pred & $96 \pm 11$ & $86 \pm 14$ \\
\hline FRC \% pred & $139 \pm 19$ & $151 \pm 17$ \\
\hline RV \% pred & $131 \pm 34$ & $143 \pm 42$ \\
\hline IC/TLC & $0.41 \pm 5$ & $0.35 \pm 6 *$ \\
\hline $\mathrm{RV} / \mathrm{TLC}$ & $0.46 \pm 0.08$ & $0.47 \pm 0.07$ \\
\hline TLco \% pred & $56 \pm 17$ & $40 \pm 14^{*}$ \\
\hline \multicolumn{3}{|l|}{ Arterial blood gases } \\
\hline $\mathrm{pH}$ & $7.42 \pm 0.04$ & $7.40 \pm 0.04$ \\
\hline $\mathrm{HCO}_{3}^{-} \mathrm{mmol} \cdot \mathrm{L}^{-1}$ & $22.8 \pm 1.9$ & $24.1 \pm 3.0$ \\
\hline $\mathrm{PaCO}_{2} \mathrm{mmHg}$ & $35.3 \pm 4.1$ & $33.3 \pm 2.8$ \\
\hline $\mathrm{PaO}_{2} \mathrm{mmHg}$ & $73.9 \pm 9.5$ & $78.7 \pm 9.2$ \\
\hline $\mathrm{SaO}_{2} \%$ & $93.2 \pm 2.1$ & $95.8 \pm 1.9$ \\
\hline \multicolumn{3}{|l|}{ Echocardiogram } \\
\hline LVEF \% & $36 \pm 9$ & $33 \pm 8$ \\
\hline Diastolic dysfunction (0/I:II/III) & $10: 11$ & $10: 13$ \\
\hline LVEDD mm & $57 \pm 7$ & $66 \pm 5^{*}$ \\
\hline LVMI $\mathrm{g} \cdot \mathrm{m}^{-2}$ & $130 \pm 54$ & $132 \pm 41$ \\
\hline LA mm & $43 \pm 5$ & $46 \pm 2$ \\
\hline $\mathrm{RV} \mathrm{mm}$ & $25 \pm 7$ & $28 \pm 6$ \\
\hline PASP mmHg & $42 \pm 14$ & $44 \pm 11$ \\
\hline TAPSE mm & $16 \pm 4$ & $17 \pm 3$ \\
\hline \multicolumn{3}{|c|}{$\begin{array}{l}\text { Data are presented as } \mathrm{n} \text { or mean } \pm \mathrm{SD} \text {. FEV1: forced expiratory volume in } 1 \mathrm{~s} ; \mathrm{FVC} \text { : forced vital capacity; IC: } \\
\text { inspiratory capacity; TLC: total lung capacity; } \mathrm{FRC} \text { : functional residual capacity; } \mathrm{RV} \text { : residual volume; } \\
T \mathrm{LCO} \text { : transfer factor of the lung for carbon monoxide; } \mathrm{pH} \text { : hydrogen-ionic potential; } \mathrm{HCO}_{3}^{-} \text {: bicarbonate; } \mathrm{PaCO}_{2} \text { : } \\
\text { arterial carbon dioxide tension; } P \mathrm{aO}_{2} \text { : arterial oxygen tension; } \mathrm{SaO}_{2} \text { : arterial oxygen saturation; } \mathrm{LVEF} \text { : left } \\
\text { ventricular ejection fraction; } \mathrm{LVEDD} \text { : left ventricular end-diastolic diameter; LVMI: left ventricular mass } \\
\text { index; LA: left atrium; RV: right ventricle; PASP: pulmonary artery systolic pressure; TAPSE: tricuspid } \\
\text { annular plane systolic excursion. *: } \mathrm{p}<0.05 \text {. }\end{array}$} \\
\hline
\end{tabular}

cardiocirculatory abnormalities were associated with higher submaximal ratings of leg discomfort as exercise progressed (figure $2 \mathrm{f})(\mathrm{p}<0.05)$.

\section{Pulmonary gas exchange and ventilatory responses to exertion}

The presence and severity of exertional hypoxaemia did not differ between the groups (table 3 ). The low $\Delta V^{\prime} \mathrm{O}_{2} / \Delta \mathrm{WR}$ group showed consistently higher ventilation at a given WR and metabolic demand $\left(V^{\prime} \mathrm{CO}_{2}\right)$ (figure $4 \mathrm{a}$ and $\mathrm{b}$ ). The higher ventilatory response was associated with a lower tidal volume (figure $4 \mathrm{c}$ ) and a progressively lower inspiratory capacity; in fact, only the low $\Delta V^{\prime} \mathrm{O}_{2} / \Delta \mathrm{WR}$ group showed a significant decrease in inspiratory capacity from rest to exercise termination (table 3 and figure $4 \mathrm{~d})(\mathrm{p}<0.05)$. Thus, they presented with higher operating lung volumes throughout exercise, leading to earlier attainment of critical inspiratory constraints (figure $4 \mathrm{e}$ ). Those ventilatory and mechanical abnormalities were associated with higher submaximal ratings of dyspnoea as exercise progressed (figure $4 f)(p<0.05)$.

\section{Discussion}

The main original findings of the present study involving patients with coexisting COPD-HF indicate that impaired aerobic function during incremental CPET, as primarily indicated by a low $\Delta V^{\prime} \mathrm{O}_{2} / \Delta \mathrm{WR}$ ratio and confirmed by a cluster of other parameters, was associated with 1) lower limits for tidal volume expansion (lower inspiratory capacity), impaired gas exchange efficiency (lower transfer factor) and a higher left ventricular end-diastolic diameter at rest; 2) excessive exertional ventilation relative to metabolic demand; 3) higher operating lung volumes leading to earlier attainment of critical inspiratory constraints; and 4) a severely impaired peak aerobic capacity. Of note, those patients provided higher ratings of leg discomfort 

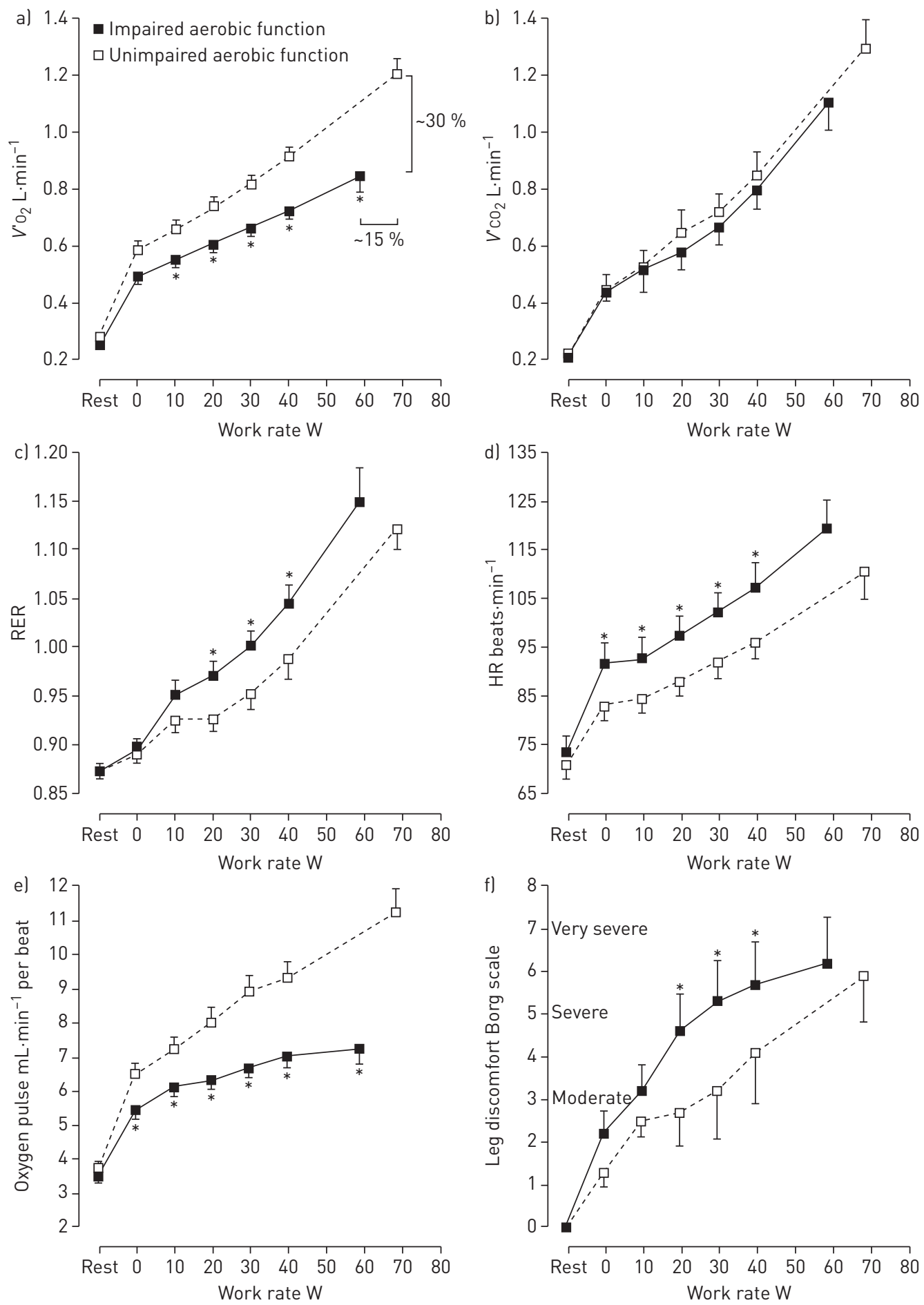

FIGURE 2 a, b and c) Metabolic; $d$ and el cardiovascular; and f) sensory responses to incremental exercise in patients presenting or not with impaired aerobic function (change in oxygen uptake $\left(\Delta V^{\prime} O_{2}\right) /$ change in work rate $(\triangle \mathrm{WR})$ below lower limit of normal). $V^{\prime} \mathrm{CO}_{2}$ : carbon dioxide output; RER: respiratory exchange ratio, $\mathrm{HR}$ : heart rate. *: $p<0.05$ (between-group differences at a given work rate.

and breathlessness at a given WR and reported lower functional capacity (NYHA class) and a greater burden of chronic dyspnoea (mMRC scale). Collectively, our results indicate that a low $\Delta V^{\prime} \mathrm{O}_{2} / \Delta \mathrm{WR}$ ratio on CPET signals deleterious cardiopulmonary-peripheral muscular interactions which are germane to patients' functional impairment in daily life.

The ramp-incremental protocol for CPET has the clinical advantage of providing estimates of the key parameters of aerobic function $\left(V^{\prime} \mathrm{O}_{2}\right.$ kinetics delay, $\Delta V^{\prime} \mathrm{O}_{2} / \Delta \mathrm{WR}$ ratio, estimated $V^{\prime} \mathrm{O}_{2}$ lactate threshold and 
TABLE 3 Physiological and sensory responses to incremental cardiopulmonary exercise testing in chronic obstructive pulmonary disease (COPD)-heart failure (HF) patients separated by the presence or not of aerobic dysfunction based on a low or preserved change in oxygen uptake $\left(\Delta V^{\prime} \mathrm{O}_{2}\right) /$ change in work rate $(\Delta \mathrm{WR})$, respectively

\begin{tabular}{|c|c|c|}
\hline & Preserved $\Delta V^{\prime} 0_{2} / \Delta W R$ & Low $\Delta V^{\prime} 0_{2} / \Delta W R$ \\
\hline Subjects $\mathrm{n}$ & 24 & 27 \\
\hline \multicolumn{3}{|l|}{ Power and metabolic } \\
\hline Peak WR W & $68 \pm 13$ & $58 \pm 12 *$ \\
\hline Peak $V^{\prime} \mathrm{O}_{2} L \cdot \min ^{-1}$ (\% pred) & $1.20 \pm 0.20(69 \pm 11)$ & $0.84 \pm 0.15(54 \pm 12)^{*}$ \\
\hline$\Delta V^{\prime} \mathrm{O}_{2} / \Delta \mathrm{WR} \mathrm{mL} \cdot \mathrm{min}^{-1} \cdot \mathrm{W}^{-1}$ & $10.8 \pm 1.3$ & $6.4 \pm 2.2^{*}$ \\
\hline $\mathrm{V}^{\prime} \mathrm{O}_{2}$ "lag phase" duration s & $72(41)$ & $124(56)^{*}$ \\
\hline Peak RER & $1.14 \pm 0.06$ & $1.12 \pm 0.05$ \\
\hline$V^{\prime} \mathrm{O}_{2}$ lactate threshold L. $\min ^{-1}$ & $0.87 \pm 0.13^{\#}$ & $0.69 \pm 0.11^{*, 9}$ \\
\hline Peak HR beats $\cdot \min ^{-1}$ & $110 \pm 15$ & $109 \pm 13$ \\
\hline HR recovery in 1 min beats $\cdot \min ^{-1}$ & $14 \pm 9$ & $8 \pm 6^{*}$ \\
\hline Peak $\mathrm{O}_{2}$ pulse $\mathrm{mL} \cdot \mathrm{min}^{-1}$. beat $^{-1}$ & $11.2 \pm 2.6$ & $7.2 \pm 2.4^{*}$ \\
\hline \multicolumn{3}{|l|}{ Ventilatory } \\
\hline Peak V'E L.min ${ }^{-1}$ & $49.2 \pm 11.7$ & $46.5 \pm 10.4$ \\
\hline Peak VT L & $1.41 \pm 0.30$ & $1.25 \pm 0.21 *$ \\
\hline Peak $f_{\mathrm{R}}$ breaths $\cdot \mathrm{min}^{-1}$ & $35 \pm 7$ & $33 \pm 6$ \\
\hline$V^{\prime} \mathrm{E} / V^{\prime} \mathrm{CO}_{2}$ nadir & $36 \pm 6$ & $43 \pm 6^{*}$ \\
\hline$V^{\prime} \mathrm{E}-V^{\prime} \mathrm{CO}_{2}$ slope & $33 \pm 7$ & $38 \pm 6^{*}$ \\
\hline$V^{\prime} \mathrm{E}-V^{\prime} \mathrm{CO}_{2}$ intercept $\mathrm{L} \cdot \mathrm{min}^{-1}$ & $2.5 \pm 3.1$ & $3.0 \pm 2.9$ \\
\hline Peak IC L & $2.24 \pm 0.27$ & $1.76 \pm 0.29 *$ \\
\hline Peak-rest IC L & $-0.20 \pm 0.24$ & $-0.38 \pm 0.30 *$ \\
\hline Peak EILV/TLC & $0.87 \pm 0.04$ & $0.90 \pm 0.03$ \\
\hline Peak EELV/TLC & $0.63 \pm 0.05$ & $0.70 \pm 0.07 *$ \\
\hline Peak IRV L & $0.69 \pm 0.26$ & $0.49 \pm 0.24^{*}$ \\
\hline \multicolumn{3}{|l|}{ Gas exchange } \\
\hline Rest $\mathrm{SpO}_{2} \%$ & $94 \pm 3$ & $95 \pm 3$ \\
\hline Peak $\mathrm{SpO}_{2} \%$ & $91 \pm 5$ & $93 \pm 4$ \\
\hline Peak - rest $\mathrm{SpO}_{2} \%$ & $-4 \pm 3$ & $-2 \pm 4$ \\
\hline \multicolumn{3}{|l|}{ Sensory } \\
\hline Peak dyspnoea score & $6.5(1.5)$ & $5.5(2)$ \\
\hline Peak leg effort score & $6(1.5)$ & $6(1.5)$ \\
\hline
\end{tabular}

Data are presented as $\mathrm{n}$, mean $\pm \mathrm{SD}$ or median (interquartile range). RER: respiratory exchange ratio; HR: heart rate; $V^{\prime} \mathrm{E}$ : minute ventilation; $V_{\mathrm{T}}$ : tidal volume; $f_{\mathrm{R}}$ : respiratory frequency; $V^{\prime} \mathrm{CO}_{2}$ : carbon dioxide output; IC: inspiratory capacity; EILV: end-inspiratory lung volume; EELV: end-expiratory lung volume; TLC: total lung capacity; IRV: inspiratory reserve volume; $\mathrm{SpO}_{2}$ : oxygen saturation by pulse oximetry. ${ }^{*}: \mathrm{p}<0.05$. ${ }^{\#}: \mathrm{n}=13$; ก: $n=14$.

peak $V^{\prime} \mathrm{O}_{2}$ ) [15] in a short time frame. This is particularly desirable for the assessment of disabled patients with cardiopulmonary diseases to whom longer or repeated constant WR tests are not feasible options. Using this testing format, we were able to identify, for the first time, a subgroup of COPD-HF patients in whom those parameters uniformly indicated poor aerobic function. Thus, after a sluggish start, $V^{\prime} \mathrm{O}_{2}$ increased less than expected for the change in power output (i.e. shallower $\Delta V^{\prime} \mathrm{O}_{2} / \Delta \mathrm{WR}$ ), leading to a more marked impairment in peak $V^{\prime} \mathrm{O}_{2}$ than peak WR (table 3). Moreover, there was an earlier shift to a predominantly anaerobic metabolism in these patients compared to their counterparts. Those abnormalities were probably instrumental to explain why those patients provided higher ratings of leg discomfort at a given WR (figure 2f).

A key interpretative issue relates to the potential mechanism(s) underlying the defining feature of the group with impaired aerobic function: a low $\Delta V^{\prime} \mathrm{O}_{2} / \Delta \mathrm{WR}$ ratio. Whereas in healthy subjects $V^{\prime} \mathrm{O}_{2}$ parallels the increase in WR, thereby allowing work efficiency to be estimated [15], a pathological decrease in $\Delta V^{\prime} \mathrm{O}_{2} / \Delta W R$ implies a lower $V^{\prime} \mathrm{O}_{2}$ cost to perform a given WR and/or progressively slower $V^{\prime} \mathrm{O}_{2}$ kinetics as WR increases, i.e. a gradually longer time for muscle $V^{\prime} \mathrm{O}_{2}$ to be represented "at the mouth" $[12,16]$. The first hypothesis is consistent with the notion of impaired muscle oxygen utilisation secondary to profound abnormalities in muscle oxidative metabolism [25]. Of note, those abnormalities have been described in patients with HF [26] or COPD [27-29]; thus, it is conceivable that severe peripheral muscular derangements impairing oxygen extraction may have contributed to decrease $\Delta V^{\prime} \mathrm{O}_{2} / \Delta \mathrm{WR}$ ratio in selected patients [30]. 

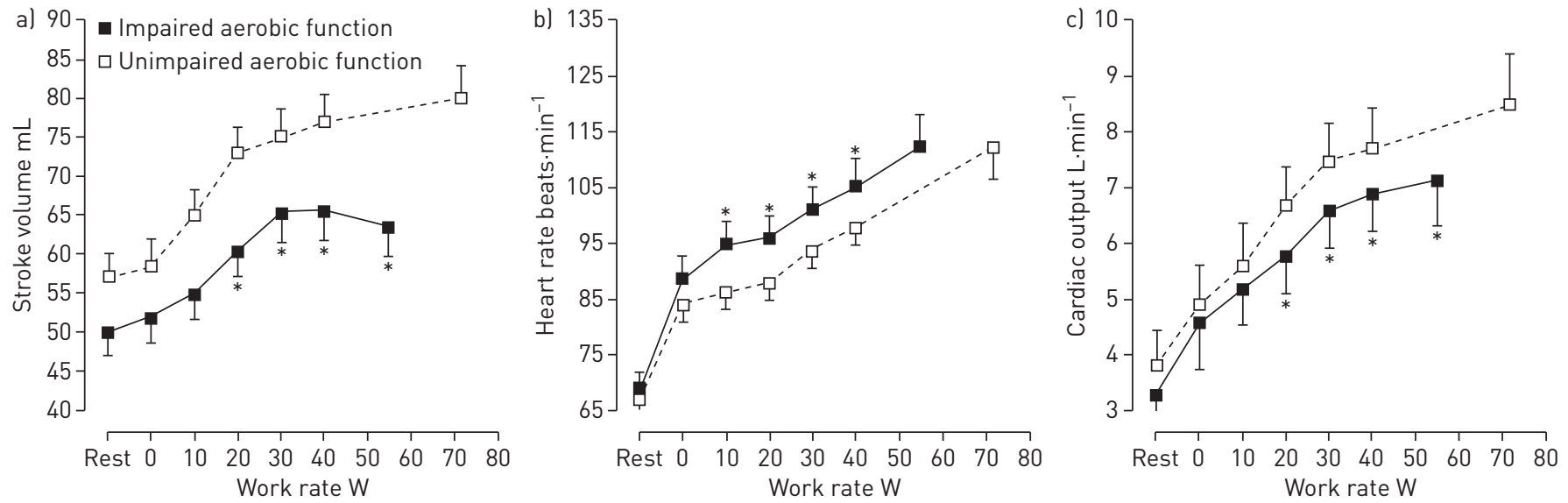

FIGURE 3 Central haemodynamic responses to incremental exercise in the subgroup of chronic obstructive pulmonary disease (COPD)-heart failure (HF) patients with cardiac impedance measurements. a) Stroke volume; b) heart rate; c) cardiac output. Patients are separated by the presence or not of impaired aerobic function (change in oxygen uptake $\left(\Delta V^{\prime} O_{2}\right) /$ change in work rate $(\Delta W R)$ below the lower limit of normal; $n=11$ and $n=10$, respectively). *: $p<0.05$.

A large body of evidence has also been accumulated in favour of a role of impaired muscle oxygen delivery (i.e. lower cardiac output under preserved arterial oxygen saturation) to decrease the $\Delta V^{\prime} \mathrm{O}_{2} / \Delta \mathrm{WR}$ relationship in patients with HF [31-33]. In fact, we found that the group with impaired aerobic function presented with similar oxygen saturation by pulse oximetry, but lower oxygen pulse (figure 2e) and stroke volume (figure 3a) than their counterparts with preserved aerobic function. The higher resting left ventricular end-diastolic diameter in the former group suggests more advanced HF [34], which may have contributed to the lower $\Delta V^{\prime} \mathrm{O}_{2} / \Delta \mathrm{WR}$. It is also conceivable that $\Delta V^{\prime} \mathrm{O}_{2} / \Delta \mathrm{WR}$ has been negatively impacted by the deleterious central haemodynamic consequences of increased operating lung volumes (figure $4 \mathrm{e}$ ) [6]. The most noticeable findings in previous investigations carried out in hyperinflated COPD patients (without HF) point to an increased right ventricular afterload and a relative underfilling of the left ventricle $[35,36]$. It is noteworthy that patients with more impaired pulmonary microvascular blood flow in the study by HuEPer et al. [37] presented with a low transfer factor, one of the few resting functional findings which differed the patients with low versus preserved $\Delta V^{\prime} \mathrm{O}_{2} / \Delta \mathrm{WR}$ (table 2), The greater inspiratory constraints found in the former group (figure 4e) signal severe neuromechanical dissociation and higher swings in intrathoracic pressure; the latter being an important mechanism of increasing left ventricular transmural pressure $[13,38]$. Indeed, we found a temporal association between oxygen pulse (figure $2 \mathrm{e}$ ) and stroke volume (figure $3 \mathrm{a}$ ) plateauing as the inspiratory reserve volume became critically low (after $\sim 30 \mathrm{~W}$ ) (figure $4 \mathrm{e}$ ). Those abnormalities were conceivably more relevant to those in need of a higher left ventricular filling volume, i.e. patients with aerobic dysfunction who presented with higher left ventricular end-diastolic diameter at rest (table 1).

Another noticeable finding that characterised the low $\Delta V^{\prime} \mathrm{O}_{2} / \Delta \mathrm{WR}$ group was an increased ventilatory response to a given $V^{\prime} \mathrm{CO}_{2}$ compared to the preserved $\Delta V^{\prime} \mathrm{O}_{2} / \Delta \mathrm{WR}$ group [5]. Of note, patients' higher $V^{\prime} \mathrm{E}$ was increased well before any indirect evidence of the lactate threshold (in fact, even at rest) (figure $4 \mathrm{a}$ ). In other words, increased $V^{\prime} \mathrm{E}$ in the low $\Delta V^{\prime} \mathrm{O}_{2} / \Delta \mathrm{WR}$ group was not only a response to a greater lactic acidotic drive (table 3), but was also influenced by higher dead space/tidal volume ratio and/or a lower arterial carbon dioxide tension $\left(\mathrm{PaCO}_{2}\right)$ set point [11]. A higher dead space/tidal volume could be partially explained by a lower tidal volume (figure 4c) due to greater inspiratory constraints (figure 4e) [39]. Other sources of afferent stimuli apart from those involved in the regulation of the physiological dead space may have also been involved, including heightened ergoreceptor [40,41] and sympathetic activation [42] in the setting of poorer muscle oxygenation in patients with aerobic impairment.

The patients in the low $\Delta V^{\prime} \mathrm{O}_{2} / \Delta \mathrm{WR}$ group presented with higher operating lung volumes throughout exercise (figure 4f). In addition to a trend towards greater "static" hyperinflation, it is noteworthy that they had worse dynamic hyperinflation than their counterparts (figure $4 \mathrm{~d}$ ). The higher submaximal ventilation (figure 4a) may have accelerated the rate of dynamic hyperinflation in these patients, leading to earlier attainment of critical inspiratory constraints and a downward shift in tidal volume (figure 4c) [39]. Thus, patients in the low $\Delta V^{\prime} \mathrm{O}_{2} / \Delta \mathrm{WR}$ group developed an unfortunate combination of abnormalities which are central to the genesis of dyspnoea in COPD [43]: a high respiratory neural drive ( higher $\left.V^{\prime} \mathrm{E}\right)$ (figure $4 \mathrm{a}$ ), which is only partially rewarded by tidal expansion (greater inspiratory constraints) (figure $4 \mathrm{c}$ and e) [44]. 

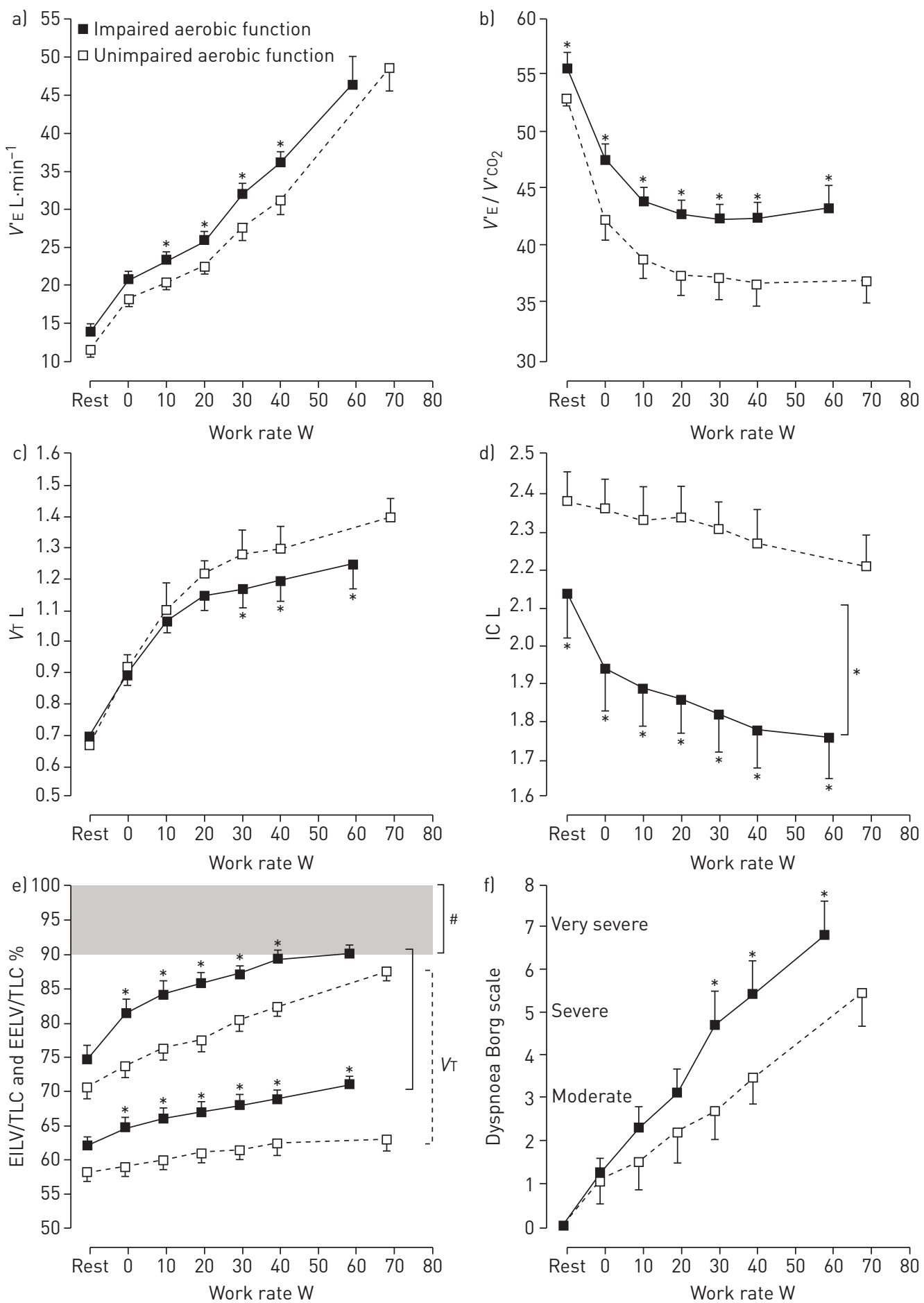

FIGURE 4 a and b) Ventilatory; c) breathing pattern; $d$ and el operating lung volumes; and f) sensory responses to incremental exercise in patients presenting or not with impaired aerobic function (change in oxygen uptake $\left(\Delta V^{\prime} \mathrm{O}_{2}\right) /$ change in work rate $(\Delta \mathrm{WR})$ below lower limit of normal). $V^{\prime} \mathrm{E}$ : minute ventilation; $V^{\prime} \mathrm{CO}_{2}$ : carbon dioxide output; $V_{T}$ : tidal volume; IC: inspiratory capacity; EILV: end-inspiratory lung volume; EELV: end-expiratory lung volume; TLC: total lung capacity. ${ }^{*}: p<0.05$ (between-group differences at a given work rate). \#: dynamic lung volumes commonly associated with critical inspiratory constraints [14].

What are the practical implications of our results? Firstly, we provided novel evidence that measurements of a submaximal, effort-independent parameter of aerobic function $\left(\Delta V^{\prime} \mathrm{O}_{2} / \Delta \mathrm{WR}\right)$ during incremental CPET provide clinically relevant information pertaining to exertional symptoms and daily functioning in patients with COPD-HF. Secondly, the negative haemodynamic consequences of higher operating lung volumes in patients with poorer cardiac function calls for the importance of maximising the deflating 
effects of bronchodilator therapy in this subgroup of patients with COPD [45]. Thirdly, strategies geared towards an improvement in oxygen delivery to and utilisation by the skeletal muscles (e.g. sildenafil [46], nitrate supplementation [47] and aerobic and muscle training [48]) are probably relevant to lessen patients' breathlessness (by lowering the ventilation stimuli) and leg muscle discomfort. Finally, the combination of a higher left ventricular end-diastolic diameter in association with lower inspiratory capacity and transfer factor (in addition to a lower $\mathrm{PaCO}_{2}$, as per our previous findings) [5] should be valued to identify the most disabled patients with COPD-HF.

We recognise some limitations of our study. Due to its non-invasive nature, our study is not particularly informative regarding to the specific effects of lung mechanical abnormalities on central haemodynamics. Despite the inherent limitation of impedance cardiography [19], it is noteworthy that stroke volume and cardiac output trajectories and values were commensurate to those expected in patients with HF (figure 3). To our knowledge, no study to date has prospectively exposed COPD-HF patients to invasive haemodynamics on exertion. In any circumstance, a study with those features would be a formidable challenge in such an unstable population. Our patients underwent a prolonged period of clinical stabilisation before study entry; moreover, most presented with repeated COPD and/or HF exacerbations, thereby postponing the CPET. It follows that our sample size, though small for epidemiological standards, reflects the real-life challenges in assessing on exertion an extremely frail population.

In conclusion, impaired aerobic function, as primarily indicated by a low $\Delta V^{\prime} \mathrm{O}_{2} / \Delta \mathrm{WR}$ during incremental CPET, discriminates a subgroup of patients with COPD-HF who are particularly symptomatic and disabled. Negative cardiopulmonary interactions conspire against a normal oxygen delivery to and utilisation by the skeletal muscles in these patients. The latter abnormalities increase the ventilatory response to exercise and, indirectly, the operating lung volumes; thus, they ultimately potentiate the central haemodynamic abnormalities. Effective strategies to fight the devastating consequences of COPD-HF should address the continuum of cardiocirculatory, pulmonary and muscular abnormalities that culminates in poor exercise tolerance and quality of life in this growing population.

Conflict of interest: None declared.

Support statement: William Spear Start Endowment Fund, Queen's University; financial support to A. Rocha was provided by Capes, Brazil; financial support to M. Marillier was provided by a long-term research fellowship from the European Respiratory Society; J.A. Neder was funded by a New Clinician Scientist Program from the Southeastern Ontario Academic Medical Association (SEAMO), Canada. The funders had no role in the study design, data collection and analysis or preparation of the manuscript.

\section{References}

1 Rutten FH, Cramer MJ, Grobbee DE, et al. Unrecognized heart failure in elderly patients with stable chronic obstructive pulmonary disease. Eur Heart J 2005; 26: 1887-1894.

2 de Torres JP, Casanova C, Marín JM, et al. Prognostic evaluation of COPD patients: GOLD 2011 versus BODE and the COPD comorbidity index COTE. Thorax 2014; 69: 799-804.

3 Oliveira MF, Arbex FF, Alencar MC, et al. Heart failure impairs muscle blood flow and endurance exercise tolerance in COPD. COPD 2016; 13: 407-415.

4 Arbex FF, Alencar MC, Souza A, et al. Exercise ventilation in COPD: influence of systolic heart failure. COPD 2016; 13: 693-699.

5 Rocha A, Arbex FF, Sperandio PA, et al. Excess ventilation in chronic obstructive pulmonary disease-heart failure overlap: implications for dyspnea and exercise intolerance. Am J Respir Crit Care Med 2017; 196: 1264-1274.

6 Neder JA, Rocha A, Alencar MCN, et al. Current challenges in managing comorbid heart failure and COPD. Expert Rev Cardiovasc Ther 2018; 16: 653-673.

7 Apostolo A, Laveneziana $\mathrm{P}$, Palange $\mathrm{P}$, et al. Impact of chronic obstructive pulmonary disease on exercise ventilatory efficiency in heart failure. Int J Cardiol 2015; 189: 134-140.

8 Rocha A, Arbex FF, Alencar MCN, et al. Physiological and sensory consequences of exercise oscillatory ventilation in heart failure-COPD. Int J Cardiol 2016; 224: 447-453.

9 Oliveira MF, Zelt JT, Jones JH, et al. Does impaired $\mathrm{O}_{2}$ delivery during exercise accentuate central and peripheral fatigue in patients with coexistent COPD-CHF? Front Physiol 2015; 5: 514.

10 Dubé B-P, Agostoni P, Laveneziana P. Exertional dyspnoea in chronic heart failure: the role of the lung and respiratory mechanical factors. Eur Respir Rev 2016; 25: 317-332.

11 Whipp BJ, Ward SA. Cardiopulmonary coupling during exercise. J Exp Biol 1982; 100: 175-193.

12 Whipp BJ. The bioenergetic and gas exchange basis of exercise testing. Clin Chest Med 1994; 15: 173-192.

13 Agostoni P, Cattadori G, Bussotti M, et al. Cardiopulmonary interaction in heart failure. Pulm Pharmacol Ther 2007; 20: 130-134.

14 O'Donnell DE, Laveneziana $\mathrm{P}$, Webb $\mathrm{K}$, et al. Chronic obstructive pulmonary disease: clinical integrative physiology. Clin Chest Med 2014; 35: 51-69.

15 Whipp BJ, Davis JA, Torres F, et al. A test to determine parameters of aerobic function during exercise. J Appl Physiol Respir Environ Exerc Physiol 1981; 50: 217-221.

16 Hansen JE, Casaburi R, Cooper DM, et al. Oxygen uptake as related to work rate increment during cycle ergometer exercise. Eur J Appl Physiol Occup Physiol 1988; 57: 140-145.

17 Vestbo J, Hurd SS, Agustí AG, et al. Global strategy for the diagnosis, management, and prevention of chronic obstructive pulmonary disease: GOLD executive summary. Am J Respir Crit Care Med 2013; 187: 347-365. 
18 American Thoracic Society, American College of Chest Physicians. ATS/ACCP statement on cardiopulmonary exercise testing. Am J Respir Crit Care Med 2003; 167: 211-277.

19 Charloux A, Lonsdorfer-Wolf E, Richard R, et al. A new impedance cardiograph device for the non-invasive evaluation of cardiac output at rest and during exercise: comparison with the "direct" Fick method. Eur J Appl Physiol 2000; 82: 313-320.

20 Beaver WL, Wasserman K, Whipp BJ. A new method for detecting anaerobic threshold by gas exchange. J Appl Physiol 1986; 60: 2020-2027.

21 Neder JA, Arbex FF, Alencar MC, et al. Exercise ventilatory inefficiency in mild to end-stage COPD. Eur Respir J 2015; 45: 377-387.

22 Palange P, Ward SA, Carlsen K-H, et al. Recommendations on the use of exercise testing in clinical practice. Eur Respir J 2007; 29: 185-209.

23 Neder JA, Nery LE, Peres C, et al. Reference values for dynamic responses to incremental cycle ergometry in males and females aged 20 to 80. Am J Respir Crit Care Med 2001; 164: 1481-1486.

24 Ponikowski P, Voors AA, Anker SD, et al. 2016 ESC Guidelines for the diagnosis and treatment of acute and chronic heart failure: the task force for the diagnosis and treatment of acute and chronic heart failure of the European Society of Cardiology (ESC). Developed with the special contribution of the Heart Failure Association (HFA) of the ESC. Eur J Heart Fail 2016; 18: 891-975.

25 Schumacker PT, Samsel RW. Oxygen delivery and uptake by peripheral tissues: physiology and pathophysiology. Crit Care Clin 1989; 5: 255-269.

26 Poole DC, Hirai DM, Copp SW, et al. Muscle oxygen transport and utilization in heart failure: implications for exercise (in)tolerance. Am J Physiol Heart Circ Physiol 2012; 302: H1050-H1063.

27 Simon M, LeBlanc P, Jobin J, et al. Limitation of lower limb $\mathrm{VO}_{2}$ during cycling exercise in COPD patients. J Appl Physiol 2001; 90: 1013-1019.

28 Medeiros WM, Fernandes MCT, Azevedo DP, et al. Oxygen delivery-utilization mismatch in contracting locomotor muscle in COPD: peripheral factors. Am J Physiol Regul Integr Comp Physiol 2015; 308: R105-R111.

29 Maltais F, Simon M, Jobin J, et al. Effects of oxygen on lower limb blood flow and $\mathrm{O}_{2}$ uptake during exercise in COPD. Med Sci Sports Exerc 2001; 33: 916-922.

30 Gimenes AC, Neder JA, Dal Corso S, et al. Relationship between work rate and oxygen uptake in mitochondrial myopathy during ramp-incremental exercise. Braz J Med Biol Res 2011; 44: 354-360.

31 Hansen JE, Sue DY, Oren A, et al. Relation of oxygen uptake to work rate in normal men and men with circulatory disorders. Am J Cardiol 1987; 59: 669-674.

32 Itoh $\mathrm{H}$, Nakamura $\mathrm{M}$, Ikeda $\mathrm{C}$, et al. Changes in oxygen uptake-work rate relationship as a compensatory mechanism in patients with heart failure. Jpn Circ J 1992; 56: 504-508.

33 Tanabe Y, Nakagawa I, Ito E, et al. Hemodynamic basis of the reduced oxygen uptake relative to work rate during incremental exercise in patients with chronic heart failure. Int J Cardiol 2002; 83: 57-62.

34 Jørgensen ME, Andersson C, Vasan RS, et al. Characteristics and prognosis of heart failure with improved compared with persistently reduced ejection fraction: a systematic review and meta-analyses. Eur J Prev Cardiol 2018; 25: 366-376.

35 Barr RG, Bluemke DA, Ahmed FS, et al. Percent emphysema, airflow obstruction, and impaired left ventricular filling. N Engl J Med 2010; 362: 217-227.

36 Smith BM, Kawut SM, Bluemke DA, et al. Pulmonary hyperinflation and left ventricular mass: the Multi-Ethnic Study of Atherosclerosis COPD Study. Circulation 2013; 127: 1503-1511.

37 Hueper K, Parikh MA, Prince MR, et al. Quantitative and semiquantitative measures of regional pulmonary microvascular perfusion by magnetic resonance imaging and their relationships to global lung perfusion and lung diffusing capacity: the Multiethnic Study of Atherosclerosis Chronic Obstructive Pulmonary Disease Study. Invest Radiol 2013; 48: 223-230.

38 Lalande $\mathrm{S}$, Johnson $\mathrm{BD}$. Breathing strategy to preserve exercising cardiac function in patients with heart failure. Med Hypotheses 2010; 74: 416-421.

39 O'Donnell DE, Elbehairy AF, Webb KA, et al. The link between reduced inspiratory capacity and exercise intolerance in chronic obstructive pulmonary disease. Ann Am Thorac Soc 2017; 14: S30-S39.

40 Ponikowski PP, Chua TP, Francis DP, et al. Muscle ergoreceptor overactivity reflects deterioration in clinical status and cardiorespiratory reflex control in chronic heart failure. Circulation 2001; 104: 2324-2330.

41 Gagnon P, Bussières JS, Ribeiro F, et al. Influences of spinal anesthesia on exercise tolerance in patients with chronic obstructive pulmonary disease. Am J Respir Crit Care Med 2012; 186: 606-615.

42 Schmidt H, Francis DP, Rauchhaus M, et al. Chemo- and ergoreflexes in health, disease and ageing. Int J Cardiol 2005; 98: 369-378.

43 Mahler DA, O'Donnell DE. Recent advances in dyspnea. Chest 2015; 147: 232-241.

44 Faisal A, Alghamdi BJ, Ciavaglia CE, et al. Common mechanisms of dyspnea in chronic interstitial and obstructive lung disorders. Am J Respir Crit Care Med 2016; 193: 299-309.

45 Hohlfeld JM, Vogel-Claussen J, Biller H, et al. Effect of lung deflation with indacaterol plus glycopyrronium on ventricular filling in patients with hyperinflation and COPD (CLAIM): a double-blind, randomised, crossover, placebo-controlled, single-centre trial. Lancet Respir Med 2018; 6: 368-378.

46 Guazzi M, Myers J, Peberdy MA, et al. Ventilatory efficiency and dyspnea on exertion improvements are related to reduced pulmonary pressure in heart failure patients receiving sildenafil. Int J Cardiol 2010; 144: 410-412.

47 Poole DC, Richardson RS, Haykowsky MJ, et al. Exercise limitations in heart failure with reduced and preserved ejection fraction. J Appl Physiol 2018; 124: 208-224.

48 Vogiatzis I, Zakynthinos S. The physiological basis of rehabilitation in chronic heart and lung disease. J Appl Physiol 2013; 115: 16-21. 